\title{
Chromosomal resistance of gonococci to antibiotics
}

\author{
C A ISON, J GEDNEY, C S F EASMON
}

From the Department of Medical Microbiology, St Mary's Hospital Medical School, London

SUMMARY Three hundred and twenty nine strains of non-penicillinase-producing Neisseria gonorrhoeae (non-PPNG) isolated from men and women were tested for their susceptibility to a range of antibiotics, and were also auxotyped and serogrouped. Nearly $6 \%(18)$ of 312 strains tested were resistant to $1 \mathrm{mg} / \mathrm{l}$ or more penicillin (compared with $4.4 \%$ of PPNG strains isolated in 1981). Many $(198,64 \%)$ strains showed intermediate resistance to penicillin $(0 \cdot 12-0.5 \mathrm{mg} / \mathrm{l})$. Nearly $5 \%$ (15) of 312 strains tested were resistant to $0.5 \mathrm{mg} / \mathrm{l}$ or more cefuroxime, and there was a high degree of cross resistance between these two antibiotics. High levels of resistance to erythromycin and tetracycline were also found, and there was also appreciable cross resistance between these antibiotics and the $\beta$ lactam drugs. Resistance to spectinomycin was rare, and there was no cross resistance between spectinomycin and other agents tested. Levels of resistance between strains isolated from different anatomical sites did not differ, except that resistance to erythromycin was greater in rectal isolates. Four main auxotypes were detected. Strains requiring arginine, hypoxanthine, and uracil $\left(\mathrm{AHU}^{-}\right)$ were more prevalent from the cervix. We have shown that there is an association between auxotype, serogroup, and level of sensitivity to penicillin, cefuroxime, and tetracycline.

The epidemiology and treatment of infections caused by penicillinase producing strains of Neisseria gonorrhoeae (PPNG) have been major concerns since the first description of these strains in $1976 .{ }^{12}$ The prevalence of infections with PPNG strains is highest in Africa and the Far East. In the United Kingdom the increase in the prevalence of PPNG strains was rapid between 1980 and 1983, but now appears to have slowed. ${ }^{3}$ Our own experience with PPNG strains isolated from patients attending the Praed Street Clinic mirrors that seen nationally, and we saw a decline in prevalence of PPNG strains in $1985 .^{4}$

Though the problem of PPNG strains has been more spectacular, resistance to antibiotics in nonPPNG strains has continued to grow, particularly in the Far East. In Thailand more than half the nonPPNG strains are resistant to $1 \mathrm{mg} / 1$ or more benzylpenicillin, and $21 \%$ are resistant to $0.5 \mathrm{mg} / \mathrm{l}$ or more cefuroxime: ${ }^{5}$ Resistance to penicillin in nonPPNG strains results from chromosomal mutations at multiple loci, each producing small increments in resistance. Some loci are specific for penicillin resistance (pen $A$ ), others mediate resistance to a

Address for reprints: Dr C A Ison, Department of Medical Microbiology, St Mary's Hospital Medical School, London W2 1PG.

Accepted for publication 9 October 1986 range of antibiotics (pen $B$ and $m t r){ }^{67}$ Thus nonPPNG strains resistant to penicillin tend to be relatively resistant to unrelated antibiotics. The mechanism of chromosomal resistance to penicillin is nonenzymic, resulting rather from alterations to penicillin binding proteins and other cell envelope structures. ${ }^{89}$

Until recently, non-PPNG strains resistant to antibiotics presented a major treatment problem only in the Far East. Recently, however, outbreaks of gonococcal infection in the USA have been caused by such strains. ${ }^{1011}$ The aims of this study were to assess the prevalence of resistance to antibiotics in non-PPNG strains isolated at this hospital and to investigate the association between resistance to antibiotics and other biological factors in these strains.

\section{Patients, materials, and methods}

SELECTION OF STRAINS

We collected 329 non-PPNG strains from patients attending the Praed Street Clinic at this hospital during 1984 and 1985. During 1984 we collected 211 strains randomly for two to three months. In January 1985 we began collecting 20 strains a month, and 118 strains were collected in January to June. Equal numbers of isolates of non-PPNG strains were collected from men and women. All strains from women (164) were isolated from the cervix, whereas strains from 
men were isolated from either the rectum (41) or the urethra (124).

\section{ISOLATION AND IDENTIFICATION}

We collected samples with disposable loops and inoculated them direct on to neisserial selective medium consisting of GC agar base (BBL), $1 \%$ IsoVitalex, and vancomycin $(3 \mathrm{mg} / \mathrm{l})$, colistin $(1000 \mathrm{u} / \mathrm{l})$, trimethoprim $(5 \mathrm{mg} / \mathrm{l})$, and amphotericin $(1.5 \mathrm{mg} / \mathrm{l})$. Agar plates were stored at $36^{\circ} \mathrm{C}$ in $7 \%$ carbon dioxide until transported to the laboratory, where they were incubated for 48 hours. Cultures were identified as being $N$ gonorrhoeae if they were oxidase positive, Gram negative cocci that produced acid from glucose, but not maltose or sucrose. The absence of penicillinase production was established by the chromogenic cephalosporin test. ${ }^{12}$

\section{MINIMUM INHIBITORY CONCENTRATION OF ANTIBIOTICS}

We estimated the minimum inhibitory concentration (MIC) of each antibiotic by an agar dilution technique. The medium was diagnostic sensitivity test (DST) agar (Oxoid) containing 1\% IsoVitalex and $5 \%$ lysed blood (Tissue Culture Services). Antibiotics were added using Adatabs (Mast Laboratories) with penicillin $(0.015$ to $2 \mathrm{mg} / \mathrm{l})$, cefuroxime $(0.015$ to 1 $\mathrm{mg} / \mathrm{l})$, tetracycline $(0.12$ to $16 \mathrm{mg} / \mathrm{l})$, erythromycin $(0.03$ to $4 \mathrm{mg} / \mathrm{l})$, or spectinomycin $(4$ to $64 \mathrm{mg} / \mathrm{l})$. The inoculum was grown overnight on neisserial medium without antibiotics, suspended in saline, and adjusted to $10^{8}$ colony forming units (cfu) $/ \mathrm{ml}$. Volumes of $1 \mu \mathrm{l}$ (containing $10^{5} \mathrm{cfu}$ ) were delivered on to each plate using a multipoint inoculator (Denley), and were incubated for 48 hours in $7 \%$ carbon dioxide at $36^{\circ} \mathrm{C}$. The highest dilution completely inhibiting growth was the MIC.

\section{AUXOTYPING}

Nutritional requirements were investigated with the chemically defined media described by Catlin. ${ }^{13}$ Strains of $N$ gonorrhoeae were grown for 24 hours at $36^{\circ} \mathrm{C}$ in $5 \%$ carbon dioxide suspended in saline and inoculated on to individual media in $1 \mu \mathrm{l}$ volumes. The plates were scored for the presence or absence of colonies after incubation for 24 hours.

\section{SEROGROUPING}

The serogroup was established with either a panel of monoclonal reagents supplied by Dr S Bygdeman or the Phadebact monoclonal GC reagent (Pharmacia). Bacteria were suspended in phosphate buffered saline and boiled for 10 minutes. Equal volumes of bacteria and antibody linked to protein A were mixed for two minutes. Strong agglutination indicated a positive result. $N$ gonorrhoeae were divided into two groups designated IA (or WI) and IB (or WII/WIII).

\section{STATISTICAL ANALYSIS}

The data were analysed using the Statistical Package for Social Sciences (SPSS). Differences between the distribution of MICs of antibiotics for strains from different anatomical sites, auxotypes, or serogroups were assessed using the Mann-Whitney test for significance between two medians. Correlation coefficients were determined using Pearson's $r$, and correlations were significant at $>0.338, p=0.01$. Differences between groups were assessed using the $\chi^{2}$ test.

\section{Results}

\section{SUSCEPTIBILITY TO ANTIBIOTICS}

Figure 1 shows the distribution of MICs of penicillin for 312 of the 329 non-PPNG strains tested. The distribution was bimodal; 18 (6\%) strains were resistant $(\geqslant 1 \mathrm{mg} / \mathrm{l}) ; 198(64 \%)$ showed intermediate levels of resistance $(0.12$ to $0.5 \mathrm{mg} / \mathrm{l})$, and $96(31 \%)$ strains were sensitive $(\leqslant 0.06 \mathrm{mg} / \mathrm{l})$. Table 1 shows the distribution of the MICs of the other four antibiotics tested. Of the 312 non-PPNG strains, $100(32 \%)$ were resistant to erythromycin $(\geqslant 1 \mathrm{mg} / \mathrm{l}), 97(31 \%)$ to tetracycline $(\geqslant 4 \mathrm{mg} / \mathrm{l}), 15(5 \%)$ to cefuroxime $(\geqslant 0.5$ $\mathrm{mg} / \mathrm{l})$, and $5(2 \%)$ to spectinomycin $(\geqslant 32 \mathrm{mg} / \mathrm{l})$.

Cross resistance between the five antibiotics is shown in table 2 by their correlation coefficients. Spectinomycin showed no cross resistance with any of the other antibiotics. There were, however, significant correlations between resistance to penicillin, tetracycline, erythromycin, and cefuroxime. The highest

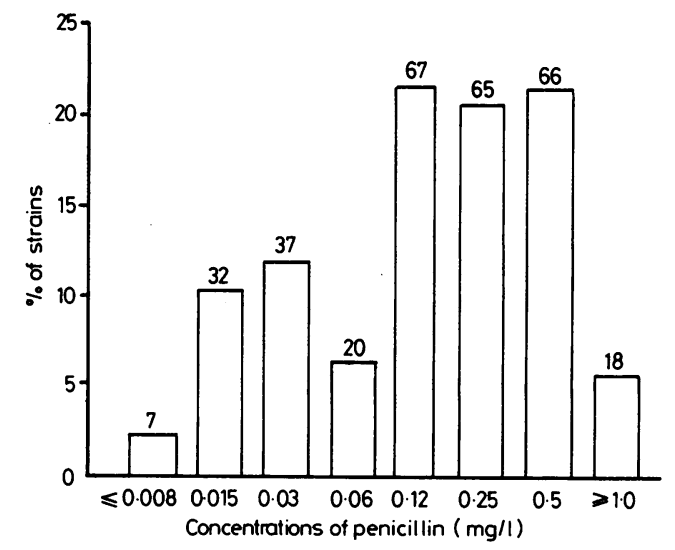

Fig 1 Distribution of minimum inhibitory concentrations (MICs) of penicillin for 312 non-PPNG strains. No of strains inhibited by each concentration shown at tops of columns. 
Table 1 Minimum inhibitory concentrations (MICs) of four antibiotics for 312 non-PPNG strains

\begin{tabular}{|c|c|c|c|c|c|c|c|c|c|c|c|c|c|}
\hline \multirow[b]{2}{*}{ Antibiotic } & \multicolumn{13}{|c|}{ No $(\%)$ concentrations (mg/l) of: } \\
\hline & $\leqslant 0.015$ & 0.03 & 0.06 & $0 \cdot 12$ & $0 \cdot 25$ & $0 \cdot 5$ & 1 & 2 & 4 & 8 & 16 & 32 & $>32$ \\
\hline $\begin{array}{l}\text { Tetracycline } \\
\text { Erythromycin } \\
\text { Cefuroxime } \\
\text { Spectinomycin }\end{array}$ & $45(14)$ & $\begin{array}{r}3(1) \\
75(24)\end{array}$ & $\begin{array}{l}46(15) \\
84(27)\end{array}$ & $\begin{array}{l}1(0 \cdot 3) \\
55(18) \\
49(16)\end{array}$ & $\begin{array}{ll}13 & (4) \\
21 & (7) \\
44 & (14)\end{array}$ & $\begin{array}{l}78(25) \\
87(28) \\
10(3)\end{array}$ & $\begin{array}{r}51(16) \\
62(20) \\
5(2)\end{array}$ & $\begin{array}{l}72(23) \\
31(10)\end{array}$ & $\begin{array}{r}82(26) \\
7(2)\end{array}$ & $13(4)$ & $2(0.6)$ & $86(28)$ & $5(2)$ \\
\hline
\end{tabular}

Table 2 Correlation coefficients (Pearson's $r$ ) showing cross resistance of 312 non-PPNG strains between antibiotics

\begin{tabular}{lllll}
\hline & Penicillin & Tetracycline & Erythromycin & Spectinomycin \\
\hline Tetracycline & $0.51^{*}$ & & & \\
Erythromycin & 0.45 & 0.63 & 0.25 & \\
Spectinomycin & 0.23 & 0.26 & 0.46 & 0.26 \\
Cefuroxime & 0.73 & 0.51 & & \\
\hline
\end{tabular}

*Pearson's $\mathrm{r}>0.338, \mathrm{p}=0.01$.

level of cross resistance was seen between penicillin and cefuroxime $(r=0.73)$ and erythromycin and tetracycline $(r=0.63)$. All isolates resistant to cefuroxime were resistant to $\geqslant 0.5 \mathrm{mg} / \mathrm{l}$ penicillin.

The differences between distributions of MICs of erythromycin for strains isolated from the various anatomical sites were significant $(p=0.01) ; 29 \%$ $(34 / 119)$ of urethral and $29 \%(46 / 154)$ of cervical isolates were sensitive (with MICs of $\geqslant 1 \mathrm{mg} / \mathrm{l}$ ) compared with $51 \%(20 / 39)$ of rectal isolates. There was no difference between the distribution of MICs of the other four antibiotics for isolates from various anatomical sites (data not shown).

\section{AUXOTYPING}

Table 3 shows that $90 \%$ (264) of 294 strains tested belonged to four major auxotypes. A further 10 strains $(3 \%)$ required proline, arginine, and uracil $\left(\mathrm{PAU}^{-}\right)$, and eight $(2 \%)$ required proline and arginine $\left(\mathrm{Pro}^{-} \mathrm{Arg}^{-}\right)$. We isolated significantly ( $\mathrm{p}=$ $0.05)$ more strains that required arginine, hypoxanthine, and uracil $\left(\mathrm{AHU}^{-}\right)$for growth from the cervix $(24 / 147,16 \%)$ than from the urethra $(9 / 110,8 \%)$ or the rectum $(1 / 37,3 \%)$.

Figure 2 shows significant $(p<0.001)$ differences in distribution of the MICs of penicillin for 241 strains of the three main auxotypes. Proline requiring $\left(\mathrm{Pro}^{-}\right)$strains were resistant to penicillin, whereas prototrophic (or wild type) strains showed intermediate levels of resistance and $\mathrm{AHU}^{-}$strains were sensitive. The same was true for tetracycline and cefuroxime (data not shown). Both prototrophic and $\mathrm{AHU}^{-}$strains were significantly $(\mathrm{p}<0.001)$ more sensitive than $\mathrm{Pro}^{-}$strains to erythromycin (data not shown).

\section{SEROGROUPING}

Most $(76 \%, 96)$ of 127 strains tested belonged to sero-
Table 3 Main four auxotypes isolated from different anatomical sites

\begin{tabular}{lllll}
\hline \multicolumn{5}{c}{ No $(\%)$ isolates from: } \\
\cline { 2 - 5 } Auxotype & $\begin{array}{l}\text { Urethra } \\
(n=110)\end{array}$ & $\begin{array}{l}\text { Rectum } \\
(n=37)\end{array}$ & $\begin{array}{l}\text { Cervix } \\
(n=147)\end{array}$ & $\begin{array}{l}\text { Total } \\
(n=294)\end{array}$ \\
\hline Prototrophic & $61(56)$ & $22(60)$ & $55(37)$ & $138(47)$ \\
"Pro- $^{-}$ & $26(24)$ & $12(32)$ & $44(30)$ & $82(28)$ \\
*AHU- $^{*}$ Arg $^{-}$ & $9(8)$ & $1(3)$ & $24(16)$ & $34(12)$ \\
\hline
\end{tabular}

${ }^{*} \mathrm{Pro}^{-}=$proline requiring; $\mathrm{AHU}^{-}=$arginine, hypoxanthine, and uracil requiring; $\mathrm{Arg}^{-}=$arginine requiring.

group IB. The associations between serogroup and auxotype were significant; $88 \%(14 / 16)$ of $\mathrm{AHU}^{-}$ strains belonged to serogroup IA, whereas $92 \%$ $(55 / 60)$ of prototrophic strains and $85 \%(23 / 27)$ of Pro $^{-}$strains were serogroup IB $(p<0.001)$. Susceptibility to antibiotics was associated with serogroup only for penicillin and cefuroxime $(p<0.001)$ and not for erythromycin $(p=0.06)$, spectinomycin $(p=0 \cdot 1)$, or tetracycline $(p=0 \cdot 25)$. Serogroup IA strains were more sensitive to penicillin and cefuroxime than serogroup IB strains, which showed higher levels of resistance.

\section{Discussion}

In 1981 we carried out a smaller survey of the susceptibility to antibiotics of non-PPNG strains. ${ }^{14}$ The bimodal distribution of sensitivity to penicillin described in this paper was also present then, but $65 \%$ of strains reported in this paper showed intermediate resistance $(0.12$ to $0.5 \mathrm{mg} / \mathrm{l})$ compared with only $30 \%$ in 1981. Because of the stepwise nature of chromosomal resistance to penicillin, the increase may reflect the prolonged general use of penicillin. It is worrying as this level of intermediate resistance to penicillin 


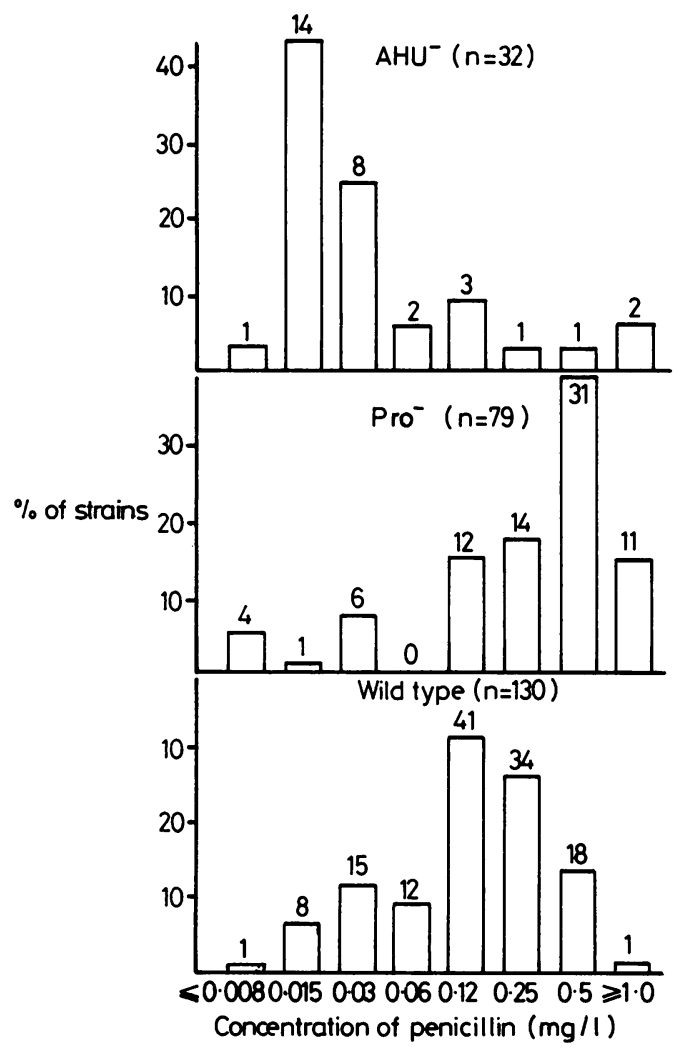

Fig 2 Distribution of minimum inhibitory concentrations (MICs) of penicillin for 241 non-PPNG strains with different auxotypes: $\mathrm{AHU}^{-}=$arginine, hypoxanthine, and uracil requiring; Pro $^{-}=$proline requiring, Wild type $=$ prototropic. No of strains inhibited by each concentration shown at tops of columns.

presages problems in treating infections with nonPPNG strains, quite apart from those caused by PPNG strains.

The overall incidence $(6 \%)$ of clinically important resistance to penicillin in non-PPNG strains $(\geqslant 1$ $\mathrm{mg} / \mathrm{l})$ was higher than that (4\%) of PPNG strains isolated at this hospital in 1981. We have not encountered clinical failures of treatment with penicillin or ampicillin, but since early 1983 only homosexual men have continued to receive ampicillin as first line treatment for gonorrhoea. The high prevalence of PPNG infections caused by PPNG strains in other groups of patients led to a change to spectinomycin. ${ }^{15}$

Apart from a few PPNG strains that were highly resistant to spectinomycin, which we think were a single clone ${ }^{16}$ low level resistance to spectinomycin was not seen. Resistance to spectinomycin was not linked with resistance to penicillin or indeed to any other antibiotic. Continued first line use of spectinomycin to control the spread of PPNG strains is therefore unlikely to stimulate broad based resistance to unrelated compounds in non-PPNG strains.

We cannot be as hopeful about cephalosporins. Though we do not know the precise level of resistance to cefuroxime that correlates with clinical failure, the high degree of cross resistance between cefuroxime and penicillin, which was also noted by Rice $e t a l,{ }^{11}$ is worrying. The genetic loci of non-enzymic resistance to cephalosporin have not been worked out, but are likely to be close to pen $A$ or pen $B$. Not only may the apparent build up of intermediate level resistance to penicillin lead to future clinical problems with cefuroxime, but the use of cefuroxime and other cephalosporins to treat gonorrhoea and limit the spread of PPNG strains may also contribute to the future build up of non-enzymic resistance to all $\beta$ lactam agents. We are now looking more closely at the genetic basis of chromosomal resistance to cephalosporins. With non-PPNG strains the $\beta$ lactamase stability of cephalosporins and related compounds is, of course, irrelevant.

Since 1981 the most dramatic change in the resistance of non-PPNG strains to other antibiotics has been to erythromycin. This has increased from only $2 \%$ of isolates resistant to $\geqslant 1 \mathrm{mg} / \mathrm{l}$ in 1981 to $32 \%$ resistant now. This is partly a reflection of the selection of strains. Unlike the 1981 survey, the study published here included 41 rectal isolates. These have been reported to be more resistant to hydrophobic molecules, such as those of erythromcyin, ${ }^{17}$ an observation that our results confirm. There has been no change in the resistance to tetracycline since 1981, but it was already at a high level then.

The number of $\mathrm{AHU}^{-}$strains isolated was unexpected. Our results confirm the close association of the $\mathrm{AHU}^{-}$auxotype with hypersensitivity to penicillin and serogroup IA reported previously. ${ }^{18-20}$ The increased prevalence of $\mathrm{AHU}^{-}$auxotype strains at the cervix is difficult to explain. During infection with a mixed population, $\mathrm{AHU}^{-}$strains may possibly be selected preferentially. They may possess other characteristics that aid survival in cervical mucus. Their lower prevalence in male urethral isolates $(8 \%)$ could be partly explained by the inclusion of strains from homosexual men. Only $20 \%$ of urethral strains isolated from men in this clinic, however, are from homosexual men. Only one $\mathrm{AHU}^{-}$auxotype nonPPNG strain was isolated from the rectum. There is evidence that rectal isolates are more resistant to hydrophobic molecules ${ }^{17}$ and belong to serogroup IB ${ }^{21}$ which may be associated with their ability to survive in a hostile environment. If $\mathrm{AHU}^{-}$strains are transmitted to the rectum, colonisation probably cannot take place. 
Chromosomal resistance to penicillin has previously been associated with $\mathrm{Pro}^{-}$strains and serogroup $\mathrm{IB}^{11}$ and was present in our strains. The association also included resistance to cefuroxime and tetracycline because of the high level of cross resistance with penicillin. Bygdeman et $a^{22}$ showed that increased resistance to penicillin was genetically linked to serogroup WII (IB) specificity. ${ }^{22}$ Auxotrophic markers have been described as being independent from susceptibility to penicillin, ${ }^{18}$ but further transformation experiments are needed to confirm this. We have found that prototrophic strains are closely associated with intermediate levels of resistance to penicillin, which echoes the findings of Knapp et al. ${ }^{18}$

We have shown changes in the pattern of sensitivity of non-PPNG strains since 1981. Constant surveillance is necessary if new trends in resistance to antibiotics are to be controlled.

This work was supported by the North West Thames Regional Health Authority and the UpJohn Company. We thank Karen Foster for her help in analysing the data.

\section{References}

1 Phillips I. $\beta$-lactamase-producing, penicillin-resistant gonococcus. Lancet 1976;ii:656-7.

2 Ashford WA, Golash RG, Hemming VG. Penicillinase producing Neisseria gonorrhoeae. Lancet 1976;ii:657-8.

3 Communicable Disease Surveillance Centre. Sexually transmitted disease surveillance in Britain: 1984. Communicable Disease Reports 1986; No 29.

4 Ison CA, Gedney J, Harris JRW, Easmon CSF. Penicillinase producing gonococci: a spent force? Genitourin Med 1986; 62:302-7.

5 Brown S, Warnnissorn T, Biddle J, Panikabutra K, Traisupa A. Antimicrobial resistance of Neisseria gonorrhoeae in Bangkok: is single drug treatment passé? Lancet 1982;ii:1366-8.

6 Sparling PF, Sarubbi FA, Blackman E. Inheritance of low-level resistance to penicillin, tetracycline, and chloramphenicol in Neisseria gonorrhoeae. J Bacteriol 1975;124:740-9.

7 Maier TW, Zubrzycki L, Coyle MB. Genetic analysis of drug resistance in Neisseria gonorrhoeae: identification and linkage relationships of loci controlling drug resistance. Antimicrob Agents Chemother 1975;7:676-81.

8 Dougherty TJ, Koller AE, Tomasz A. Penicillin-binding proteins of penicillin-susceptible and intrinsically resistant Neisseria gonorrhoeae. Antimicrob Agents Chemother 1980;18:730-7.

9 Barbour AG. Properties of penicillin-binding proteins in Neisseria gonorrhoeae. Antimicrob Agents Chemother 1981; 19:316-22.

10 Faruki H, Kohmescher RN, McKinney WP, Sparling PF. A community based outbreak of infection with penicillin resistant Neisseria gonorrhoeae not producing penicillinase (chromosomally mediated resistance). $N$ Engl J Med 1985;313:607-11.

11 Rice RJ, Biddle JW, JeanLouis YA, DeWitt WE, Blount JH, Morse SA. Chromosomally mediated resistance in Neisseria gonorrhoeae in the United States: results of surveillance and reporting, 1983-1984. J Infect Dis 1986;153:340-5.

12 O'Callaghan CH, Morris A, Kirby SM, Shingler AH. Novel method for detection of beta-lactamase by using a chromogenic cephalosporin substrate. Antimicrob Agents Chemother 1972;1:283-8.

13 Catlin BW. Nutritional profiles for Neisseria gonorrhoeae, Neisseria meningitidis and Neisseria lactamica in chemically defined media and the use of growth requirements for gonococcal typing. J Infect Dis 1973;128:178-94.

14 Herzog C, Ison CA, Easmon CSF. Antimicrobial sensitivity of Neisseria gonorrhoeae: comparison of penicillinase producing and non-penicillinase producing strains. British Journal of Venereal Diseases 1983;59:289-92.

15 McCutchan JA, Adler MW, Berrie JRH. Penicillinase producing Neisseria gonorrhoeae in Great Britain 1977-81: alarming increase in incidence and recent development of endemic transmission. Br Med J 1982;285:337-40.

16 Easmon CSF, Forster GE, Walker GD, Ison CA, Harris JRW, Munday PE. Spectinomycin as initial treatment for gonorrhoea. Br Med J 1984;289:1032-4.

17 Morse SA, Lysko PG, McFarland L, et al. Gonococcal strains from homosexual men have outer membranes with reduced permeability to hydrophobic molecules. Infect Immun 1982;37:432-8.

18 Knapp JS, Thornsberry C, Schoolnik G, Wiesner PJ, Holmes KK. Phenotypic and epidemiologic correlates of auxotypes in Neisseria gonorrhoeae. J Infect Dis 1978;138:160-5.

19 Bygdeman S. Antibiotic susceptibility of Neisseria gonorrhoeae in relation to serogroups. Acta Pathol Microbiol Scand [B] 1981;89:227-37.

20 Sandstrom E, Buchanan TM. Coagglutination class reagents identifies the same antigens as the principal outer membrane protein serotyping. In: Danielsson D, Normark S, eds. Genetics and immunobiology of pathogenic neisseriae. Umea, Sweden: European Molecular Biology Organisation, 1980:67-71.

21 Reid KG, Young H. Serogrouping Neisseria gonorrhoeae: correlation of coagglutination serogroup WII with homosexually acquired infection. British Journal of Venereal Diseases 1984;60:302-5.

22 Bygdeman S, Backman M, Danielsson D, Norgren M. Genetic linkage between serogroup specificity and antibiotic resistance in Neisseria gonorrhoeae. Acta Pathol Microbiol Immunol Scand [B] 1982;90:243-50. 